\title{
Anionic Copolymerization of Methyl Methacrylate and Other Methacrylates by $n$-BuLi in Toluene and THF
}

\author{
Heimei Yuki, Yoshio Oкамото, Koji Ohta, and Koichi Hatada \\ Department of Chemistry, Faculty of Engineering Science, Osaka \\ University, Toyonaka, Osaka, Japan.
}

(Received May 14, 1974)

\begin{abstract}
KEY WORDS Anionic Copolymerization / Methyl Methacrylate / Methacrylates / $n$-BuLi / Monomer Reactivity Ratio / Tacticity /
\end{abstract}

\begin{abstract}
A number of studies have been done on the stereospecific polymerizations of methyl $1^{1-4}$ and other methacrylates ${ }^{5-11}$ by anionic initiators, and it has been found that the polymerizations are influenced by many factors, such as the type of solvent, the initiator, etc. However, there have been few reports on the anionic copolymerizations of methacrylates. ${ }^{12-14}$ In the present work, the authors investigated the anionic copolymerizations of methyl methacrylate (MMA, $\mathbf{M}_{1}$ ) and other methacrylates $\left(\mathrm{M}_{2}\right)$, such as benzyl (BMA), $d l$ - $\alpha$-methylbenzyl (MBMA), diphenylmethyl (DP MA), $\alpha, \alpha$-dimethylbenzyl (DMMA), and trityl methacrylate (TMA) in order to study the effects of the ester group on the reactivity of the monomer and the stereoregularity of the copolymer. The copolymerizations were carried out in toluene and THF using $n$-BuLi as initiator at $-78^{\circ} \mathrm{C}$. It was found that the monomer reactivity ratios, $r_{1}$ and $r_{2}$, depended very much on the structure of the ester group and the solvent. The triad tacticity of the copolymers was predominantly isotactic in toluene and syndiotactic in THF.
\end{abstract}

MBMA, DPMA, and DMMA were prepared from methacryloyl chloride and the corresponding carbinols; TMA was prepared from silver methacrylate and trityl chloride. ${ }^{7}$ The reaction was stopped in less than 10-\% yield in the copolymerizations for the determination of $r_{1}$ and $r_{2}$. The copolymers were precipitated in methanol. Copolymer compositions were determined mainly from the pmr spectra of the copolymers. Monomer reactivity ratios were calculated by the least square method according to the Fineman-Ross equation, and the confidence limits were calculated at $90-\%$ confidence coefficient. The copolymer was converted to poly(methyl methacrylate) (PMMA) by hydrolysis followed by methylation, and the pmr spectrum of the PMMA was measured on a JEOL 100$\mathrm{MHz}$ spectrometer (JNM-MH-100) in deuterochloroform at $60^{\circ} \mathrm{C}$ by using TMS as an internal standard. The tacticity of the copolymers was obtained from the pmr spectrum of the PMMA.

The pmr spectra of all of the copolymers composed of nearly equimolar $M_{1}$ and $M_{2}$ showed a rather broad peak due to the methoxy group of MMA unit; the chemical shifts of MMA unit were slightly different from that of PMMA. Furthermore, the methoxy resonance of copoly(MMA-BMA), for instance, shifted upfield linearly from $\delta 3.61 \mathrm{ppm}$ to 3.45 as the fraction of MMA in the copolymer decreased. These spectral data suggest that the monomer distribution in the copolymer is more or less random.

A summary of the monomer reactivity ratios is shown in Table I. The monomer reactivity ratios were strongly affected by the solvent, and in several cases the reactivity in toluene was reversed in THF. The order of the reactivity $\left(1 / r_{1}\right)$ of the monomers towards MMA anion was $\mathrm{DPMA} \approx \mathrm{BMA}>\mathrm{MMA}>\mathrm{MBMA}>\mathrm{TMA}>$ DMMA in toluene and TMA $\geq$ BMA $>$ MMA $\geq$ DPMA $>$ MBMA $>$ DMMA in THF. The compositions of the oligomers which were isolated in 2-4-\% yield in the copolymerizations of MMA-BMA were also examined. They were quite similar to those of the corresponding co- 
polymers obtained in toluene and THF, although the pmr spectra of the oligomers showed peaks due to a terminal $n$-butyl group. In toluene, TMA and DMMA, which have a bulky tertiary ester group, were much less reactive than the other monomers. In THF, however, these groups did not seem to play an important role. In this solvent the reactivity of the monomers is roughly explained by the inductive effect, although there exists no good correlation between the reactivity and Taft's $\sigma^{*}$, which is well correlated to the ${ }^{13} \mathrm{C}$ chemical shifts of $\beta$ carbons

Table I. Monomer reactivity ratios for anionic copolymerizations of $\operatorname{MMA}\left(\mathbf{M}_{1}\right)$ and methacrylates $\left(\mathrm{M}_{2}\right)$ by $n$-BuLi at $-78^{\circ} \mathrm{Ca}$

\begin{tabular}{llllll}
\hline & \multicolumn{2}{c}{ In toluene } & & \multicolumn{2}{c}{ In THF } \\
\cline { 2 - 3 } \cline { 5 - 6 } & $r_{1}$ & $r_{2}$ & & $r_{1}$ & $r_{2}$ \\
\hline
\end{tabular}

$\begin{array}{lllll}\text { BMA } & 0.59 \pm 0.07 & 1.60 \pm 0.42 & 0.70 \pm 0.06 & 1.46 \pm 0.36\end{array}$

$\begin{array}{lllll}\text { MBMA } & 1.68 \pm 0.17 & 0.78 \pm 0.32 & 2.04 \pm 0.16 & 1.52 \pm 0.25\end{array}$

$\begin{array}{lllll}\text { DPMA } & 0.57 \pm 0.15 & 0.55 \pm 0.61 & 1.11 \pm 0.22 & 1.57 \pm 0.61\end{array}$

DMMA $19.1 \pm 4.0 \quad 0.56 \pm 0.392 .59 \pm 1.35 \quad 2.00 \pm 1.10$

$\begin{array}{llllllllll}\text { TMA } & 6.28 \pm 0.30 & 0.13 \pm 0.07 & 0.62 \pm 0.08 & 0.62 \pm 0.32\end{array}$

a [Monomers]/[Solvent], $1.0 \mathrm{~mol} / \mathrm{l} ;$ [Monomers]/[nBuLi], ca. 50. of the methacrylates. ${ }^{15}$

It has been shown that in the anionic polymerization of MMA the reactivity of active species in the initial stage will be different from that of the later stage of the reaction. ${ }^{16}$ Therefore, the monomer reactivity ratio might vary as the reaction progresses. However, in the present work all the copolymer composition data showed smooth curves, indicating that the $r_{1}$ and $r_{2}$ values obtained have validity at least for the initial stage of the copolymerization.

The tacticity of the copolymers is shown in Table II together with that of the homopolymers obtained under similar conditions. The copolymers were predominantly isotactic in toluene and syndiotactic in THF. This tendency is the same as that of the homopolymers except for TMA, which formed a highly isotactic polymer even in THF. ${ }^{7}$

The copolymerizations between equimolar amounts of $\mathrm{M}_{2}$ monomers were also carried out for a long time at $-78^{\circ} \mathrm{C}$. The results are shown in Table III. Since the yieids of several copolymerizations in toluene were low, one may discuss the reactivity of the monomers. It is found from the $\mathrm{M}_{2}{ }^{\prime} / \mathrm{M}_{2}$ ratio in copolymer that the order of the reactivity was $\mathrm{BMA} \geq \mathrm{MBMA}>$

Table II. Tacticity of copolymers of $\mathrm{MMA}\left(\mathbf{M}_{1}\right)$ and methacrylates $\left(\mathbf{M}_{2}\right)$ obtained by $n$-BuLi at $-78^{\circ} \mathrm{C}$ a

\begin{tabular}{|c|c|c|c|c|c|c|c|c|c|c|}
\hline \multirow{3}{*}{ Solvent } & \multirow{3}{*}{$\mathrm{M}_{2}$} & \multirow{3}{*}{$\begin{array}{l}\text { Yield, } \\
\text { wt } \%\end{array}$} & \multirow{3}{*}{ in copolymer } & \multirow{3}{*}{$\begin{array}{c}\eta_{\mathrm{sp} / C, \mathrm{c}} \\
\mathrm{d} l / \mathrm{g}\end{array}$} & \multicolumn{6}{|c|}{ Tacticity, $\%$} \\
\hline & & & & & \multicolumn{3}{|c|}{ Copolymer } & \multicolumn{3}{|c|}{$\mathbf{M}_{2}$ homopolymer } \\
\hline & & & & & $I$ & $H$ & $S$ & $I$ & $H$ & $S$ \\
\hline Toluene & BMA & 91 & 0.92 & 0.32 & 84 & 10 & 6 & 81 & 15 & 4 \\
\hline Toluene & MBMA & 75 & 1.05 & 0.49 & 66 & 27 & 7 & 56 & 35 & 9 \\
\hline Toluene & DPMA & 58 & 0.50 & 0.30 & 80 & 16 & 4 & 99 & 1 & 0 \\
\hline Toluene & DMMA & 26 & 0.19 & 0.56 & 61 & 25 & 14 & 68 & 18 & 13 \\
\hline Toluene & TMA & $24^{b}$ & 0.16 & 0.36 & 74 & 17 & 9 & 96 & 2 & 2 \\
\hline Toluene & None & 87 & - & - & - & - & - & 70 & 17 & 13 \\
\hline THF & BMA & 91 & 0.85 & 0.44 & 8 & 34 & 58 & 6 & 31 & 63 \\
\hline THF & MBMA & 91 & 0.98 & 0.56 & 7 & 37 & 56 & 8 & 32 & 60 \\
\hline THF & DPMA & 92 & 0.84 & 0.42 & 6 & 30 & 64 & 2 & 11 & 87 \\
\hline THF & DMMA & 88 & 0.87 & 0.28 & 7 & 31 & 62 & 8 & 30 & 62 \\
\hline THF & TMA & $100^{b}$ & 1.0 & 0.12 & 19 & 40 & 41 & 94 & 4 & 2 \\
\hline THF & None & 83 & - & - & - & - & - & 6 & 40 & 54 \\
\hline
\end{tabular}

a $\left[\mathrm{M}_{1}\right]_{0}=\left[\mathrm{M}_{2}\right]_{0}, 2.5 \mathrm{mmol}$; solvent, $10 \mathrm{ml}$; $[n-\mathrm{BuLi}], 0.25 \mathrm{mmol}$; time, $24 \mathrm{hr}$.

b Time, $48 \mathrm{hr}$.

c In toluene at $30.0^{\circ} \mathrm{C} ; C, 0.5 \mathrm{~g} / \mathrm{d} l$. 


\section{Anionic Copolymerization of Methacrylates}

Table III. Tacticity of copolymers of methacrylates obtained by $n$-BuLi at $-78^{\circ} \mathrm{C}^{\mathrm{a}}$

\begin{tabular}{|c|c|c|c|c|c|c|c|c|}
\hline \multirow{2}{*}{$\mathrm{M}_{2}$} & \multirow{2}{*}{$\mathrm{M}_{2}^{\prime}$} & \multirow{2}{*}{ Solvent } & \multirow{2}{*}{$\begin{array}{l}\text { Yield, } \\
\text { wt } \%\end{array}$} & \multirow{2}{*}{$\begin{array}{c}\mathbf{M}_{2}{ }^{\prime} / \mathbf{M}_{2} \\
\text { in copolymer }\end{array}$} & \multirow{2}{*}{$\begin{array}{l}\eta_{\mathrm{sp}} / C, \mathrm{c} \\
\mathrm{d} l / \mathrm{g}\end{array}$} & \multicolumn{3}{|c|}{ Tacticity, \% } \\
\hline & & & & & & $I$ & $H$ & $S$ \\
\hline BMA & MBMA & Toluene & 98 & 0.90 & 0.67 & 79 & 15 & 6 \\
\hline BMA & DPMA & Toluene & 98 & 1.06 & 0.46 & 79 & 16 & 5 \\
\hline BMA & DMMA & Toluene ${ }^{b}$ & 40 & 0.17 & - & 69 & 21 & 10 \\
\hline BMA & TMA & Toluene $^{b}$ & 34 & 0.11 & 0.27 & 81 & 12 & 7 \\
\hline TMA & MBMA & Toluene & 26 & 4.17 & 0.27 & 59 & 28 & 13 \\
\hline TMA & DPMA & Toluene $^{b}$ & 46 & - & - & 72 & 20 & 8 \\
\hline TMA & DMMA & Toluene $^{b}$ & 24 & 0.70 & 0.30 & 41 & 37 & 22 \\
\hline BMA & MBMA & THF & 84 & 1.02 & 0.40 & 8 & 27 & 65 \\
\hline BMA & DPMA & THF & 93 & 1.06 & - & 6 & 26 & 68 \\
\hline BMA & DMMA & THF & 98 & 1.10 & - & 13 & 40 & 47 \\
\hline BMA & TMA & THF & 94 & 0.94 & 0.11 & 16 & 40 & 44 \\
\hline TMA & MBMA & THF & 90 & 1.08 & 0.07 & 22 & 39 & 39 \\
\hline TMA & DPMA & THF & 97 & - & - & 26 & 35 & 39 \\
\hline TMA & DMMA & THF & 94 & 1.19 & 0.07 & 38 & 41 & 21 \\
\hline
\end{tabular}

a $\left[\mathrm{M}_{2}\right]_{0}=\left[\mathrm{M}_{2}^{\prime}\right]_{0}, 2.5 \mathrm{mmol}$; solvent, $10 \mathrm{ml} ; n-\mathrm{BuLi}, 0.25 \mathrm{mmol}$; time, $24 \mathrm{hr}$.

b Time, $48 \mathrm{hr}$.

c In toluene at $30.0^{\circ} \mathrm{C} ; \mathrm{C}, 0.5 \mathrm{~g} / \mathrm{d} l$.

TMA > DMMA, which is the same as that determined by the $r_{1}$ values. The data on the tacticity of these copolymers are given in Table III. The copolymers were also predominantly isotactic in toluene and syndiotactic in THF, except for copoly(TMA-DMMA), which had nearly equal $I$ and $H$ contents regardless of the solvents. However, the stereoregularity of the copolymers, in many cases, was between those of the corresponding homopolymers or less than both, in particular, the copolymers composed of bulky monomers like TMA and DMMA had poor regularity. The structure of the ester groups apparently affects the stereoregularity of the copolymers as well as the homopolymers. However, the details of the effect are not clear at the present time.

Acknowledgment. The authors are very grateful to Messrs. Y. Inoue, K. Obayashi, S. Okabe, and S. Nakashima for their help in the laboratory work.

\section{REFERENCES}

1. T. G. Fox, B. S. Garrett, W. E. Goode, S. Gratch, J. F. Kincaiel, A. Spell, and J. D. Stroupe, J. Amer. Chem. Soc., 80, 1768 (1958).
2. D. L. Glusker, R. G. Galluccio, and R. A. Evans, ibid., 86, 187 (1964).

3. W. Fowells, C. Schuerch, F. A. Bovey, and F. P. Hood, ibid. 89, 1396 (1967).

4. Y. Inoue, R. Chujo, and A. Nishioka, Polymer J., 2, 13 (1971).

5. H. Sobue, K. Matsuzaki, and S. Nakano, $J$. Polym. Sci., Part A, 2, 3339 (1964).

6. T. Tsuruta, T. Makimoto, and H. Kanai, J. Macromol. Chem., 1, 31 (1966).

7. H. Yuki, K. Hatada, T. Niinomi, and Y. Kikuchi, Polymer J., 1, 36 (1970).

8. T. Ito, K. Aoshima, F. Toda, K. Uno, and Y. Iwakura, ibid., 1, 278 (1970).

9. J. Junquera, N. Cardona, and J. E. Figueruelo, Makromol. Chem., 160, 159 (1972).

10. B. Wesslen, G. Gunneby, G. Hellström, and P. Svedling, J. Polym. Sci. Part C, 42, 457 (1973).

11. H. Yuki, K. Ohta, K. Ono, and S. Murahashi, ibid. Part A-1, 6, 829 (1968).

12. K. Ito, T. Sugie, and Y. Yamashita, Makromol. Chem., 125, 291 (1969).

13. J. C. Bevington, D. O. Harris, and F. S. Rankin, Eur. Polym. J., 6, 725 (1970).

14. P. Vlcek, D. Doskocilova, and J. Trekoval, J. Polym. Sci., Part C, 42, 231 (1973).

15. H. Yuki, et al., unpublished data.

16. D. M. Wiles and S. Bywater, Polymer, 3, 175 (1962). 